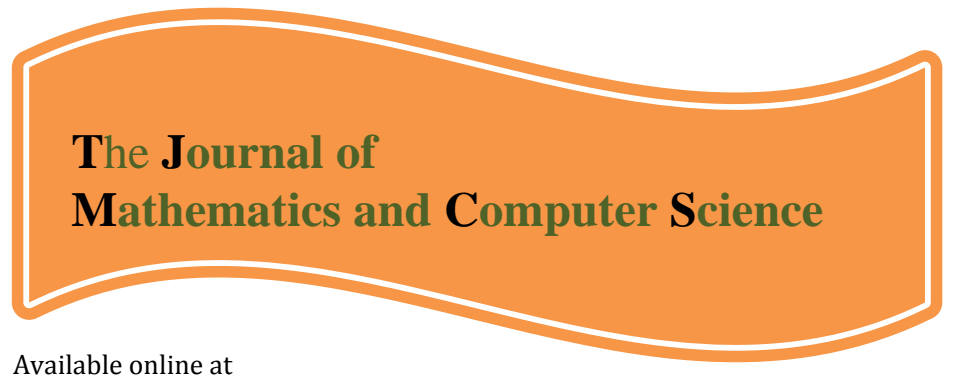

http://www.TJMCS.com

The Journal of Mathematics and Computer Science Vol .2 No.1 (2011) 111-121

\title{
Supplier selection based on supplier risk: An ANP and fuzzy TOPSIS approach
}

\author{
Ali Shemshadi ${ }^{1,}$, Mehran Toreihi' ${ }^{2}$, Hossein Shirazi ${ }^{3}$, M. J. Tarokh ${ }^{4}$ \\ K. N. Toosi University of Tech, shemshadi@sina.kntu.ac.ir \\ K. N. Toosi University of Tech, mtoreihi@sina.kntu.ac.ir \\ Malek Ashtar University of Tech, shirazi@mut.ac.ir \\ K. N. Toosi University of Tech, mj.tarokh@kntu.ac.ir
}

Received: September 2010, Revised: December 2010

Online Publication: January 2011

\begin{abstract}
Typically, supplier selection constitutes one of the most important stages of supply chain management and a variety of basic and hybrid MCDM approaches have been deployed to provide this problem with well-suited solutions. This paper investigates a new novel approach for this problem based on ANP and fuzzy TOPSIS methods while it takes into account the risk factor solely regarding the decision maker's venture strategy. In addition to an ANP model that determines the effects of decision criteria, in the proposed approach, a set of 5 risk categories has been deployed to affect the decision maker's choice by normalizing the weights of risk criteria.
\end{abstract}

Keywords: Supplier selection, Supplier risk, Analytic network process, Fuzzy TOPSIS.

\footnotetext{
$1,{ }^{*}$ Corresponding author: Postgraduate student at the department of information technology \& industrial engineering, K. N. Toosi University of Technology, Tehran, Iran.

${ }^{2}$ Postgraduate student at the department of information technology \& industrial engineering, K. N. Toosi University of Technology, Tehran, Iran.

${ }^{3}$ Associate Professor at the department of information and communication technology, Malek Ashtar University of Technology, Tehran, Iran.

${ }^{4}$ Associate Professor at the department of information technology \& industrial engineering, K. N. Toosi University of Technology, Tehran, Iran.
} 


\section{Introduction}

Complexity of the dynamic supply chain in the information era has caused a significant impact on the supply chain management and consequently, on the supply chain risk. Harald et al. (2003) has outlined four factors as the main drivers: product/service complexity, e-business, outsourcing and globalization. The top three drivers of supply chain risk noted by Thun \& Hoenig (2009) are globalization, product variants and outsourcing. In the past, risk was easier to manage because most of the manufactures sold products directly to customers, but in today's technology-mediated environment, no firm stands alone.

Supplier selection is the entry point of the supply chain process that starts from purchasing materials to delivering products to the customers. According to AMR research (2007) on risk factors, regardless of industry, supplier failure is the top issue that firms worry about. One of the main concerns of every company is to minimize disruption to its supply chain.

In literature, supplier selection has been treated as a Multiple Criteria Decision Making (MCDM) and a wide range of mathematical methods have been undertaken to provide the problems with sufficient and more accurate solutions (Boer et al., 2001; Ho et al., 2010). Table 1 enlists and categorizes these methods.

Each supplier's reliability depends on the upstream business for supplies and services while, in turn, the reliability of every one of these suppliers relies on upper level suppliers and so on. As a result, a reliability chain exists along supply chains. This means that not only the reliability of suppliers should take into account, but also, the reliability of supplier's suppliers can influence the business indirectly. In other words, today's global firms face "interdependence vulnerabilities", which means that not only must they consider about their own potential risks, but also about the vulnerabilities to their suppliers (Foroughi et al., 2006). For example, the 1995 earthquake in Kobe, Japan, had a widespread impact on the companies such as Eli Lilly, Caterpillar, Texas Instruments, and IBM. It also affected companies like Apple Computer, who had to slow down production of PowerBook computers due to disruption of the production of display monitors in Kobe (Foroughi et al., 2006). Robert Bosch, a German components supplier, delivered its customers with defective high pressure pumps for diesel fuel injection systems in the beginning of 2005 because of the mistake of a sub-supplier (Thun \& Hoenig, 2009).

Table 1-Multiple approaches deployed for supplier selection problem

\begin{tabular}{|c|c|c|}
\hline Category & Method & References \\
\hline \multirow{3}{*}{$\begin{array}{l}\text { Artificial Intelligence \& } \\
\text { Knowledge Discovery }\end{array}$} & Genetic Algorithm & $\begin{array}{l}\text { Liao \& Rittscher (2007); } \\
\text { Chen \& Wang (2008); } \\
\text { Hwang \& Rau (2008) }\end{array}$ \\
\hline & Artificial Neural Networks & $\begin{array}{l}\text { Wei et al. (1997); } \\
\text { Wu et al. (2008); } \\
\text { Lee \& Ou-Yang (2009); } \\
\text { Chen et al. (2009) }\end{array}$ \\
\hline & Data Mining & Kai et al. (2009) \\
\hline \multirow{5}{*}{$\begin{array}{l}\text { Mathematical Programming } \\
\text { Methods }\end{array}$} & Data Envelopment Analysis & Wu (2009) \\
\hline & Linear Programming & $\begin{array}{l}\text { Amid et al. (2006); } \\
\text { Guneri et al. (2009) }\end{array}$ \\
\hline & AHP and Nonlinear Programming & Kokangul \& Susuz (2009) \\
\hline & Rough set theory & Chang et al. (2007) \\
\hline & Grey system theory & Huixia \& Tao (2008) \\
\hline \multirow{3}{*}{$\begin{array}{l}\text { MCDM } \\
\text { and } \\
\text { GMCDM }\end{array}$} & AHP & $\begin{array}{l}\text { Xia \& Wu (2007); } \\
\text { Lee (2009); } \\
\text { Chamodrakas et al. (2010) }\end{array}$ \\
\hline & ANP & $\begin{array}{l}\text { Gencer \& Gürpinar (2007); } \\
\text { Luo et al. (2009); } \\
\text { Razmi et al. (2009) }\end{array}$ \\
\hline & TOPSIS & $\begin{array}{l}\text { Boran et al. (2009); } \\
\text { Rhee et al. (2009) }\end{array}$ \\
\hline
\end{tabular}


According to Harland et al. (2003) and Knemeyer et al. (2009), supply chain risk, as showed in the following equation, is the probability of an event, times the business impact or the severity of that event.

Risk $=$ Probability (of an event) $\times$ Business Impact (loss)

Oke \& Gopalakrishnan (2009), classified risk to three categories: a) High likelihood, low impact b) Medium likelihood, moderate impact c) Low likelihood, High impact. Goankar \& Viswanadham (2007) identified three broad forms of risk mentioned as deviation, disruption and disaster that conforms to those classified by Oke \& Gopalakrishnan (2009). Tang \& Tomlin (2008) described two types of supply risks known as supply cost risks and supply commitment risks. They also mentioned political/social risk in the case of globalization. Harland et al. (2003) introduced eleven types of risks and six types of losses. Another classification of probabilities and impacts provided by Hallikas et al. (2004) extends categorization in Oke \& Gopalakrishnan (2009) by adding extra assumptions. Table 2 illustrates the aforementioned classification by Hallikas et al. (2004) and table 3 summarizes the supplier risk factors mentioned in the literature.

Table 2-Business impact and probability of a risk

\begin{tabular}{|c|c|c|c|}
\hline \multicolumn{2}{|c|}{ Impact assessment scale } & \multicolumn{2}{|c|}{ Probability assessment scale } \\
\hline Rank & Subjective estimate & Rank & Subjective estimate \\
\hline 1 & No impact & 1 & Very unlikely \\
\hline 2 & Minor impact & 2 & Improbable \\
\hline 3 & Medium impact & 3 & Moderate \\
\hline 4 & Serious impact & 4 & Probable \\
\hline 5 & Catastrophic impact & 5 & Very Probable \\
\hline
\end{tabular}

Table 3-Supplier risk factors

\begin{tabular}{|c|c|c|}
\hline Reference & Risk factors/Risk classification & Domain \\
\hline Knemeyer et al. (2009) & $\begin{array}{l}\text { Natural accidents (fire, earthquake); } \\
\text { Normal accidents (technology failure); } \\
\text { Abnormal accidents (ill-will by insides/outsides) }\end{array}$ & $\begin{array}{l}\text { Catastrophic } \\
\text { events }\end{array}$ \\
\hline $\begin{array}{l}\text { Oke \& } \\
\text { Gopalakrishnan (2009) }\end{array}$ & $\begin{array}{l}\text { Imports; } \\
\text { Climate; } \\
\text { Man-made disasters; } \\
\text { Natural disasters; } \\
\text { Socio-economic; } \\
\text { Loss of key suppliers } \\
\end{array}$ & $\begin{array}{l}\text { Retail supply } \\
\text { chain }\end{array}$ \\
\hline Tang \& Tomlin (2008) & $\begin{array}{l}\text { Supply cost risks; } \\
\text { Supply commitment risks; } \\
\text { Political/Social risks; }\end{array}$ & Supply risks \\
\hline Thun \& Hoenig (2009) & $\begin{array}{l}\text { Strike; } \\
\text { Natural disaster; } \\
\text { War; } \\
\text { Terrorist attack; } \\
\text { Increasing customs duty; } \\
\text { Import restriction; } \\
\text { Oil crisis; } \\
\text { Accident (like fire); } \\
\end{array}$ & $\begin{array}{l}\text { German } \\
\text { automotive } \\
\text { industry }\end{array}$ \\
\hline Chan \& Kumar (2007) & $\begin{array}{l}\text { Geographical location; } \\
\text { Political stability; } \\
\text { Economy; } \\
\text { Terrorism; } \\
\end{array}$ & $\begin{array}{l}\text { Global supplier } \\
\text { selection }\end{array}$ \\
\hline Li et al. (2008) & $\begin{array}{l}\text { Time delay; } \\
\text { Technology; } \\
\text { Flexibility; } \\
\text { Reliability; } \\
\text { Compatibility; } \\
\text { Ease of use for product; }\end{array}$ & $\begin{array}{l}\text { Real estate } \\
\text { company }\end{array}$ \\
\hline Levary (2008) & $\begin{array}{l}\text { Supplier reliability; } \\
\text { Country risk; } \\
\text { Reliability of transportation; } \\
\text { Reliability of supplier's suppliers; }\end{array}$ & $\begin{array}{l}\text { Manufacturer } \\
\text { ranks foreign } \\
\text { suppliers }\end{array}$ \\
\hline Micheli et al. (2009) & $\begin{array}{l}\text { Capacity constraints; } \\
\text { Cost reduction capabilities; }\end{array}$ & $\begin{array}{l}\text { Supplier related } \\
\text { risk sources }\end{array}$ \\
\hline
\end{tabular}




\begin{tabular}{|l|l|l|}
\hline & Lead time; & Environmental performance; \\
& Financial health; & Failure to meet delivery requirements; \\
& Inbound transportation; & \\
& Information systems compatibility and sophistication Inventory & \\
& management; & \\
& Management vision; & \\
& Process technological changes; & \\
\hline
\end{tabular}

On the other side, fuzzy set theory, which was introduced by Zadeh (1965) to map linguistic variables to numerical variables, has emerged as a powerful mathematical tool today and has been applied in many applied researches such as (Chen, 2005; Hsiao, 2008). We are going to deploy this theory in our model in order to propose a more applied decision making algorithm.

Reviewing ANP and Fuzzy TOPSIS methods in section 2, we are going to describe the proposed method in section 3. A simple numerical example is provided in section 4, followed by a more complex and more realistic case in section 5 .

\section{Basic Methods}

\subsection{ANP}

Analytic network process (ANP) was developed by Thomas L. Saaty and is used for multi-criteria decision making (MCDM) problems. ANP is a general framework to deal with decision problems without making assumptions about the independence of the clusters or elements (Saaty, 1999). A sample of an ANP model is shown in figure 1.

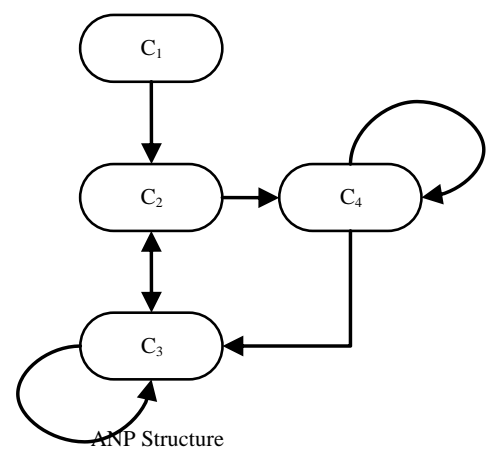

Figure 1. Sample of ANP model

The network structure of the ANP makes possible the representation of any decision problem without concern for what comes first and what comes next as in a hierarchy.

\subsection{Fuzzy TOPSIS}

The TOPSIS (technique for order performance by similarity to ideal solution) is a solution to MCDM problem. According to this technique, the best alternative would be the one that is nearest to the positive ideal solution (PIS) and farthest from the negative ideal solution (NIS). The PIS is a solution that maximizes the benefit criteria and minimizes the cost criteria and the NIS is vice versa. This section extends TOPSIS to the fuzzy environment, which was introduced by Zadeh (1965) to map linguistic variables to numerical variables.

Definition 1. Let $\tilde{a}=\left(a_{1}, a_{2}, a_{3}\right)$ and $\tilde{b}=\left(b_{1}, b_{2}, b_{3}\right)$ be two triangular fuzzy numbers, then the vertex method is defined to calculate the distance between them as equation 2 .

$d(\tilde{a}, \tilde{b})=\sqrt{\frac{1}{3}\left[\left(a_{1}-b_{1}\right)^{2}+\left(a_{2}-b_{2}\right)^{2}+\left(a_{3}-b_{3}\right)^{2}\right]}$

Definition 2. Considering the different importance values for each criterion, the weighted normalized fuzzy decision matrix is constructed as: 
$\tilde{V}=\left[\tilde{v}_{i j}\right]_{m \times n} \quad i=1,2, \ldots, n \quad j=1,2, \ldots m$

where $\tilde{v}_{i j}=\tilde{r}_{i j} \otimes w_{i}$

Fuzzy TOPSIS steps can be outlined as follows:

Step 1. Choose the linguistic ratings $\left(\tilde{x}_{i j} \quad i=1,2, \ldots, n \quad j=1,2, \ldots m\right)$ for alternatives with respect to criteria. To obtain normalized decision matrix $R$ let:

$\tilde{x}_{i j}=\left(a_{i j}, b_{i j}, c_{i j}\right) \quad \tilde{x}_{j}^{-}=\left(a_{j}^{-}, b_{j}^{-}, c_{j}^{-}\right) \quad$ and $\quad \tilde{x}_{j}^{*}=\left(a_{j}^{*}, b_{j}^{*}, c_{j}^{*}\right)$

then $\tilde{r}_{i j}=\left\{\begin{array}{l}\frac{x_{i j}}{\tilde{x}_{j}^{*}}=\left(\frac{a_{i j}}{a_{j}^{*}}, \frac{b_{i j}}{b_{j}^{*}}, \frac{c_{i j}}{c_{j}^{*}}\right) \\ \frac{\tilde{x}_{j}^{-}}{x_{i j}}=\left(\frac{a_{j}^{-}}{a_{i j}}, \frac{b_{j}^{-}}{b_{i j}}, \frac{c_{j}^{-}}{c_{i j}}\right)\end{array}\right.$

Step 2. Calculate the weighted normalized fuzzy decision matrix. The weighted normalized value $\tilde{v}_{i j}$ calculated by equation (3).

Step 3. Identify the fuzzy positive ideal solution (FPIS) and the fuzzy negative ideal solution (FNIS). In this paper our criteria is risk based, so FPIS would be the minimum value and FNIS would be the maximum value.

Step 4. Calculate the distance of each alternative from FPIS and FNIS as mentioned in equations (5) and (6).

$D_{j}^{*}=\sum_{j=1}^{m}\left(\tilde{v}_{i j}, \tilde{v}_{j}^{*}\right) \quad j=1,2, \ldots, m$

$D_{j}^{-}=\sum_{j=1}^{m}\left(\widetilde{v}_{i j}, \tilde{v}_{j}^{-}\right) \quad j=1,2, \ldots, m$

Step 5. Calculate similarities to ideal solution.

$C C_{j}=\frac{D_{j}^{-}}{D_{j}^{*}+D_{j}^{-}}$

Step 6. Rank alternatives according to $C C_{j}$ in descending order.

\section{The Proposed Model}

We have categorized risks into five groups as illustrated in table 4. There are three linguistic values hidden in this categorization known as high, medium and low. Figure 2 shows another view of risk categorization which reveals that this grouping is consists of probability or the likelihood of an event and its impact or loss as in equation (1).

Table 4-Risk categorization

\begin{tabular}{|l|l|}
\hline Risk Category & Definition \\
\hline HH & High likelihood, high impact \\
\hline MM & Medium likelihood, moderate impact \\
\hline HL & High likelihood, low impact \\
\hline LH & Low likelihood, high impact \\
\hline LL & Low likelihood, low impact \\
\hline
\end{tabular}




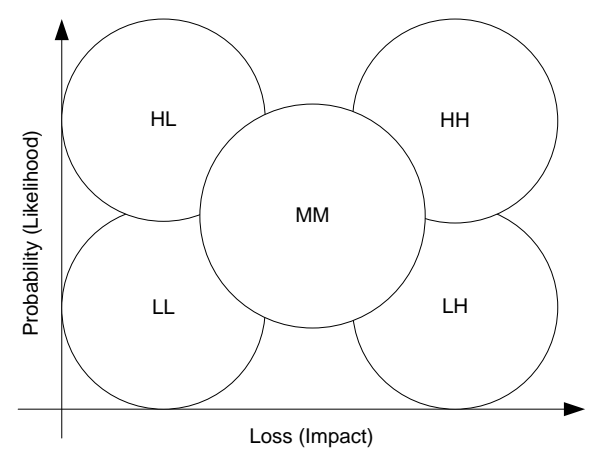

Figure 2. Risk categorization

In our proposed model, we use ANP for comparison of criteria to get the normalized weight of each risk criteria. This part takes the impact factor of the risk into consideration. Then, using a fuzzy TOPSIS approach, we rank the alternatives based on the probability issue and the calculated weights of the criteria. Fuzzy sets theory in this phase helps us to deal with uncertainty of the alternatives evaluation. Figure 3 shows the triangular fuzzy numbers used.

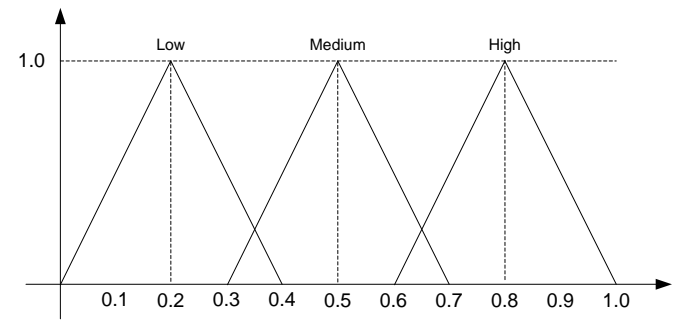

Figure 3. Triangular fuzzy numbers

The proposed approach is illustrated in 9 steps as follows:

Step 1: Identify the potential suppliers.

At the first step we provide a list of known potential suppliers denoted by $A_{i}$ where $i=(1,2, \ldots, m)$.

Step 2: Identify the risk criteria of the specified business domain.

The risk criteria could be simply denoted by $C_{j}$ where $j=(1,2, \ldots, n)$.

Step 3: Model the risk criteria as an ANP problem and define the relationships between the clusters and the elements.

Step 4. Weight the criteria using paired comparison as illustrated in ANP

In this step we calculate the normalized weight of each criteria (i.e. risk factor) denoted by $W_{j}$ where $j=(1,2, \ldots, n)$.

Step 5: Evaluate the alternatives using linguistic variables and convert the linguistic values to their equivalent triangular fuzzy numbers.

Each alternative is evaluated against all risk criterions by the decision maker(s) who merely deploy linguistic terms. Later, the linguistic evaluation results are converted to numerical terms.

Step 6: Determine the weighted decision matrix $D$.

$D=\left[d_{i j}\right]_{m \times n}$

$d_{i j}=(a, b, c)$

$d_{i j}=\tilde{r}_{i j} \otimes w_{i}$ 
Step 7: Calculate the Positive Ideal Solution (PIS) and Negative Ideal Solution (NIS) for every risk factor.

$$
\begin{aligned}
& P I S_{j}=\left(a_{j}^{*}, b_{j}^{*}, c_{j}^{*}\right) \\
& N I S_{j}=\left(a_{j}^{-}, b_{j}^{-}, c_{j}^{-}\right) \\
& a_{j}^{*}=\min _{i}\left\{a_{i j}\right\} \\
& b_{j}^{*}=\min _{i}\left\{b_{i j}\right\} \\
& c_{j}^{*}=\min _{i}\left\{c_{i j}\right\} \\
& a_{j}^{-}=\max _{i}\left\{a_{i j}\right\} \\
& b_{j}^{-}=\max _{i}\left\{b_{i j}\right\} \\
& c_{j}^{-}=\max _{i}\left\{c_{i j}\right\}
\end{aligned}
$$

Step 8: Calculate the distance of each alternative from PIS and NIS and determine the closeness coefficient for each alternative.

$$
\begin{aligned}
& D_{j}^{*}=\sqrt{\Delta a_{i j}^{* 2}+\Delta b_{i j}^{* 2}+\Delta c_{i j}^{* 2}} \\
& D_{j}^{-}=\sqrt{\Delta a_{i j}^{-2}+\Delta b_{i j}^{-2}+\Delta c_{i j}^{-2}} \\
& C C_{j}=\frac{D_{j}^{-}}{D_{j}^{*}+D_{j}^{-}}
\end{aligned}
$$

Step 9: Rank the alternatives according to their closeness coefficient in a descending order.

\section{Numerical example}

In this section we are going to clarify our model using a numerical example. There are five risk factors and four alternatives in this example. The goal is to rank the alternatives based on their risks so that the supplier (alternative) with the lowest supply risk can be chosen at the end.

Step 1: There are four suppliers or alternatives known as A1, A2, A3 and A4.

Step 2: Risk criteria of the alternatives considered in this example are defined as follow:

- Country risk (CR)

- Financial risk (FR)

- Natural disasters (ND)

- Technology risk (TR)

- Delivery risk (DR)

Step 3: The ANP problem is modeled in the following network.

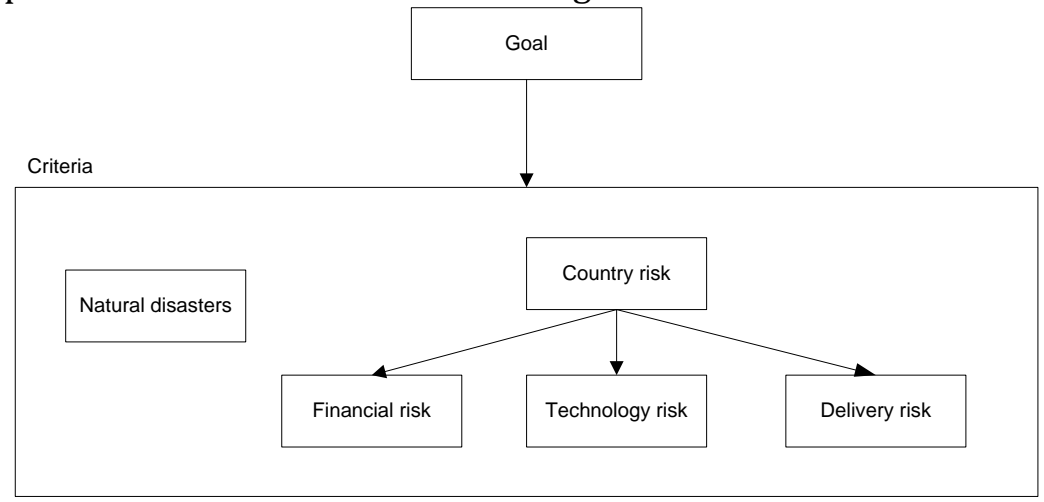

Figure 4-Criteria relationships as an ANP diagram 
Step 4: We have used Super Decisions software in this step to calculate the weights of the criteria.

$$
W=\underset{\text { criteria }}{\text { alternatives }}\left[\begin{array}{ccc}
0 & 0 & 0 \\
W_{11} & W_{12} & 0 \\
0 & 0 & 0
\end{array}\right]
$$

Figure 5 - Super-matrix of the ANP problem

\begin{tabular}{|llllll|}
\hline & CR & FR & ND & TR & DR \\
CR & 1 & 1 & $1 / 3$ & 4 & 3 \\
FR & 1 & 1 & $1 / 3$ & 3 & 5 \\
ND & 3 & 3 & 1 & 6 & 4 \\
TR & $1 / 4$ & $1 / 3$ & $1 / 6$ & 1 & $1 / 4$ \\
DR & $1 / 3$ & $1 / 5$ & $1 / 4$ & 4 & 1 \\
\hline
\end{tabular}

Table 5-Paired comparison of criteria with respect to goal $\left(W_{11}\right)$

\begin{tabular}{|llll|}
\hline & FR & TR & DR \\
\hline FR & 1 & 1 & $1 / 3$ \\
TR & 1 & 1 & $1 / 5$ \\
DR & 3 & 5 & 1 \\
\hline
\end{tabular}

Table 6-Paired comparison of criteria with respect to country risk $\left(W_{22}\right)$

\begin{tabular}{|ll|}
\hline Criteria & Weights \\
\hline Country risk & 0.163 \\
Financial risk & 0.215 \\
Natural disasters & 0.368 \\
Technology risk & 0.067 \\
Delivery risk & 0.187 \\
Sum & 1.000 \\
\hline
\end{tabular}

Table 7-Total weights of criteria (normalized)

Step 5: Evaluating the alternatives using linguistic values. Then, these values have changed to their equivalent fuzzy numbers.

Step 6: Calculate the weighted decision matrix for alternatives.

\begin{tabular}{|llllll|}
\hline & CR & FR & ND & TR & DR \\
\hline A1 & $(0.098,0.130,0.163)$ & $(0.064,0.107,0.150)$ & $(0.000,0.074,0.147)$ & $(0.020,0.033,0.047)$ & $(0.056,0.093,0.131)$ \\
A2 & $(0.000,0.033,0.065)$ & $(0.064,0.107,0.150)$ & $(0.110,0.184,0.258)$ & $(0.000,0.013,0.029)$ & $(0.112,0.150,0.187)$ \\
A3 & $(0.049,0.081,0.114)$ & $(0.000,0.043,0.086)$ & $(0.221,0.294,0.368)$ & $(0.020,0.033,0.047)$ & $(0.000,0.037,0.075)$ \\
A4 & $(0.000,0.033,0.065)$ & $(0.064,0.107,0.150)$ & $(0.110,0.184,0.258)$ & $(0.040,0.054,0.067)$ & $(0.000,0.037,0.075)$ \\
\hline
\end{tabular}

Table 8-Weighted evaluation matrix for alternatives

Step 7: Calculate the PIS and NIS.

\begin{tabular}{|llllll|}
\hline & CR & FR & ND & TR & DR \\
\hline FPIS & $\widetilde{\boldsymbol{v}}_{\mathbf{1}}^{*}=(0,0,0)$ & $\widetilde{\boldsymbol{v}}_{\mathbf{1}}^{*}=(0,0,0)$ & $\widetilde{\boldsymbol{v}}_{\mathbf{1}}^{*}=(0,0,0)$ & $\widetilde{\boldsymbol{v}}_{\mathbf{1}}^{*}=(0,0,0)$ & $\widetilde{\boldsymbol{v}}_{\mathbf{1}}^{*}=(0,0,0)$ \\
FNIS & $\widetilde{\boldsymbol{v}}_{\mathbf{1}}^{-}=(1,1,1)$ & $\widetilde{\boldsymbol{v}}_{\mathbf{1}}^{-}=(1,1,1)$ & $\widetilde{\boldsymbol{v}}_{\mathbf{1}}^{-}=(1,1,1)$ & $\widetilde{\boldsymbol{v}}_{\mathbf{1}}^{-}=(1,1,1)$ & $\widetilde{\boldsymbol{v}}_{\mathbf{1}}^{-}=(1,1,1)$ \\
\hline
\end{tabular}

Table 9-Fuzzy positive ideal solution and fuzzy negative ideal solution

Step 8: Calculate the distance of each alternative from PIS and NIS and determine the closeness coefficient for each alternative. 


\begin{tabular}{|lll|}
\hline Alternatives & $D_{j}^{*}$ & $D_{j}^{-}$ \\
\hline A1 & 1.0852 & 6.6684 \\
A2 & 0.8641 & 6.8098 \\
A3 & 0.8690 & 6.8079 \\
A4 & 0.7567 & 6.9210 \\
\hline
\end{tabular}

Table 10-Distances of alternatives to PIS and NIS

$$
\begin{aligned}
& C C_{j}=\frac{D_{j}^{-}}{D_{j}^{*}+D_{j}^{-}}=\frac{6.6684}{1.0852+6.6684}=0.8600 \\
& \begin{array}{|ll|}
\hline \text { Alternatives } & C C_{j} \\
\hline \text { A1 } & 0.8600 \\
\text { A2 } & 0.8874 \\
\text { A3 } & 0.8868 \\
\text { A4 } & 0.9014
\end{array}
\end{aligned}
$$

Table 11-Closeness coefficient value for alternatives

Step 9: Rank the alternatives according to their closeness coefficient in a descending order.

\begin{tabular}{|ll|}
\hline Rank & Alternative \\
\hline 1 & A4 \\
2 & A2 \\
3 & A3 \\
4 & A1 \\
\hline
\end{tabular}

The results show that A4 is the best supplier with the lowest supply risk.

\section{Conclusion remarks and suggestions}

Within the previous pages of this paper we went through a discussion on a hybrid MCDM method based on ANP and Fuzzy TOPSIS to enhance previous solutions for the problem of selecting the best supplier from a set of potential alternatives based on risk factor. The proposed model takes advantage of ANP generally to determine weights and specifically to investigate impact of risk factors on each other. The results are affected by the decision maker's strategy, which in turn denotes company's appeal to decide based on loss or probability of variety of risk categories for each alternative. The final solution is obtained through a few steps based on fuzzy TOPSIS method.

The proposed method takes advantage of conformance with the company's strategy while it is solely based on the risk factor. On the other side, the required preliminary study to model each supplier's risk is a difficult process, thus it is a constraint for this method. Finally a numerical example has been proposed to investigate the properties of the proposed approach. To provide an outline for the next step and develop a more applied approach, the proposed approach could be generalized to take into account nonrisk decision making criteria with a broader set of categories and strategic factors. In addition, the proposed method also could be integrated into supply chain management and coordination applications' decision processes such as (Shemshadi et al., 2008; Soroor et al., 2009) and provide them with a well suited supplier selection process.

\section{References}

Amid, A., Ghodsypour, S. H., O’Brien, C. (2006). Fuzzy multiobjective linear model for supplier selection in a supply chain. International Journal of Production Economics, 104, 394-407

AMR, 2007. AMR Research Report on Major Supply Chain Risk Factors. AMR Research Inc.

Boer, L. d., Labro, E., Morlacchi, P. (2001). A review of methods supporting supplier selection. European Journal of Purchasing \& Supply Management 7, pp 75-89.

Boran, F. E., Genc, S., Kurt, M., Akay, D. (2009). A multi-criteria intuitionistic fuzzy group decision making for supplier selection with TOPSIS method. Expert Systems with Applications, 36, 11363-11368.

Chamodrakas , I., Batis, D., Martakos, D. (2010) Supplier selection in electronic marketplaces using satisficing and fuzzy AHP. Expert Systems with Applications, 37, 490-498. 


\section{Ali Shemshadi, Mehran Toreihi, Hossein Shirazi, M. J. Tarokh/ TJMCS Vol .2 No.1 (2011) 111-121}

Chen, C.Y. (2005). Fuzzy logic derivation of neural network models with time delays in subsystems, International Journal on Artificial Intelligence Tools 14: 967

Chan, F. T.S., Kumar, N. (2007). Global supplier development considering risk factors using fuzzy extended AHPbased approach. The International Journal of Management Science, 35, 417-431.

Chang, B., Hung, H. F., Lo, C. C. (2007).Supplier Selection Using Rough Set Theory. Proceedings of the IEEE IEEM, 1461-1465.

Chen, Z.H., Wang, H.S. (2008). Supplier selection and supply quantity allocation of common and non-common parts with multiple criteria under multiple products. Computers \& Industrial Engineering, 55. pp110-133.

Chen, K, Xuan, Z., Shang, X. (2009). Selection of Suppliers based on BP Neutral Networks and Grey Correlation Analysis. International Joint Conf. on Artificial Intelligence, pp 268-271.

Cheng, E. W.L., Li, H. (2007). Application of ANP in process models: An example of strategic partnering. Building and Environment, 42, 278-287.

Dağdeviren, M., Yavuz, S., Kılınc, N. (2009). Weapon selection using the AHP and TOPSIS methods under fuzzy environment. Expert Systems with Applications, 36, 8143-8151.

Fofoughi, A., Albin, M., Kocakulah, M. (2006). Perspectives on Global Supply Chain Supply-Side Risk Management. Proceedings of PICMET 2006, 2732-2740.

Gaonkar, R. S., Viswanadham, N. (2007). Analytical framework for the Management of Risk in Supply Chains. IEEE Transactions on Automation Science and Engineering, Vol. 4, No. 2, 265-273.

Gencer, C., Gürpinar, D. (2007). Analytic network process in supplier selection: A case study in an electronic firm. Applied mathematical modeling, 31, 2475-2486.

Guneri, A. F., Yucel, A., Ayyildiz, G. (2009). An integrated fuzzy-lp approach for a supplier selection problem in supply chain management. Expert Systems with Applications, 36, 9223-9228

Hallikas, J., Karvonen, I., Pulkkinen, U., Virolainen, V.M. (2004). Risk management processes in supplier networks. International Journal of Production Economics, 90, 47-58

Hallikas, J., Puumalainen, K., Vesterinen, T., Virolainen, V.M. (2005). Risk-based classification of supplier relationships. Journal of Purchasing and Supply Management, 11, 72-82.

Harland, C., Brenchley, R., Walker, H. (2003). Risk in supply networks. Journal of Purchasing \& Supply Management, 9 , 51-62.

Ho, W., Xu, X., Dey, P. K. (2010). Multi-criteria decision making approaches for supplier evaluation and selection: A literature review. European Journal of Operational Research, 202, pp 16-24.

Hsiao, F.H. (2008). Robustness design of fuzzy control for nonlinear multiple time-delay largescale systems via neural-network-based approach. IEEE Transactions on Systems Man And Cybernetics, Part BCybernetics $38: 244$ DOI 10.1109/TSMCB.2006.890304

Huixia, Z., Tao, Y. (2008). Supplier Selection Model based on the Grey System Theory. The International Conf. on Risk Management \& Engineering Management, 100-104.

Hwang, M. H., Rau, H. (2008). Development of a Supplier Selection Approach from the Viewpoint of the Entire Supply Chain. Proceedings of the Seventh International Conference on Machine Learning and Cybernetics, 3938-3945.

Kai, Z., Xin, Y., Dao-ping, W. (2009).Study on CBR Supplier Selection System Based On Data Mining for Oil Enterprises. International Symposium on Information Engineering and Electronic Commerce. pp 555-559.

Knemeyer, M. A., Zinn, W., Eroglu, C. (2009). Proactive planning for catastrophic events in supply chains. Journal of Operations Management, 27, 141-153.

Kokangul, A., Susuz, Z. (2009). Integrated analytical hierarch process and mathematical programming to supplier selection problem with quantity discount. Applied Mathematical Modelling, 33, 1417-1429.

Lee, A. H. I. (2009). A fuzzy supplier selection model with the consideration of benefits, opportunities, costs and risks. Expert Systems with Applications, 36, 2879-2893.

Lee, C. C., Ou-Yang, C. (2009). A neural networks approach for forecasting the supplier's bid prices in supplier selection negotiation process. Expert Systems with Applications, 36, pp 2961-2970.

Levary, R. R. (2008). Using the analytic hierarchy process to rank foreign suppliers based on supplier risks. Computers \& Industrial Engineering, 55, 535-542.

Li, C.H., Sun, Y.H., Du, Y.w. (2008). An ANP with Benefits, Opportunities, Costs and Risks for Selecting Suppliers. IEEE 978-1-4244-2108.

Liao, Z., Rittscher, J. (2007). Integration of supplier selection, procurement lot sizing and carrier selection under dynamic demand conditions. International Journal of Production Economics, 107, pp 502-510. 
Ali Shemshadi, Mehran Toreihi, Hossein Shirazi, M. J. Tarokh/ TJMCS Vol .2 No.1 (2011) 111-121

Luo , X., Wu, C., Rosenberg, D., Barnes, D. (2009). Supplier selection in agile supply chains: An informationprocessing model and an illustration. Journal of Purchasing \& Supply Management, Article in press. doi:10.1016/j.pursup.2009.05.004

Micheli, G. J.L., Cagno, E., Giulio, A. D. (2009). Reducing the total cost of supply through risk-efficiency-based supplier selection in the EPC industry. Journal of Purchasing and Supply Management, 15, 166-177.

Oke, A., Gopalakrishnan, M. (2009). Managing disruptions in supply chains: A case study of a retail supply chain. International Journal of Production Economics, 118, 168-174.

Önüt, S., Kara, S. S., Işik, E. (2009). Long term supplier selection using a combined fuzzy MCDM approach: A case study for a telecommunication company. Expert Systems with Applications, 36, 3887-3895.

Razmi, J., Rafiei, H., Hashemi, M. (2009). Designing a decision support system to evaluate and select suppliers using fuzzy analytic network process. Computers \& Industrial Engineering, 57, 1282-1290.

Rhee, B. v. d., Verma, R., Plaschka, G. (2009). Understanding trade-offs in the supplier selection process: The role of flexibility, delivery, and value-added services/support. International Journal of Production Economics, 120, 3041.

Saaty, T. L. (1999). Fundamentals of the Analytic Network Process. ISAHP Japan, pp. 12-14

Saaty, T. L., (1996), Decision Making with Dependence and Feedback: The Analytic Network Process, RWS Publications, Pittsburgh.

Soroor, J., Tarokh, M. J., Shemshadi, A. (2009). "Initiating a state of art system for real-time supply chain coordination", European Journal of Operational Research, Vol. 196, Issue 2, pp. 635-650.

Shemshadi, A., Soroor, J., Tarokh, M. J. (2008) "Implementing a Multi-Agent System for the Real-time Coordination of a Typical Supply Chain Based on the JADE Technology", $3^{\text {rd }}$ IEEE SMC International Conference on System of Systems Engineering (SoSE'08), 1-6.

Tang, C., Tomlin, B. (2008). The power of flexibility for mitigating supply chain risks. International Journal of Production Economics, 116, 12-27.

Thun, J.-H., Hoenig, D. (2009). An empirical analysis of supply chain risk management in the German automotive industry. International Journal of Production Economics,doi:10.1016/j.ijpe.2009.10.010

Wei, S., Zhang, J., Li, Z. (1997). A Supplier-selecting System Using a Neural Network. IEEE International Conf. on Intelligent Processing Systems, pp 468-471.

Wu, J. J., Liu, G., Xi, C. Y. (2008). The Study on Agile Supply Chain-based Supplier Selection and Evaluation. International Symposium on Information Science and Engineering, 280-284.

Wu, D. (2009). Supplier selection: A hybrid model using DEA, decision tree and neural network. Expert Systems with Applications, 36, 9105-9112.

Xia, W., Wu, Z. (2007). Supplier selection with multiple criteria in volume discount environments. Omega, 35, 494 504.

Zadeh, L. A. (1965). Fuzzy sets. Information and Control, 8, 338-353.

Zadeh, L. A. (1975). The concept of a linguistic variable and its application to approximate reasoning. Information Sciences, 8. pp. 199-249(I), 301-357(II).

Zsidisin, G. A. (2003). A grounded definition of supply risk. Journal of Purchasing \& Supply Management, 9, 217-224. 